\title{
THE INFLUENCE OF DARWIN ON PSYCHOLOGY.
}

BY PROFESSOR JAMES ROWLAND ANGELL,

The University of Chacago.

I.

Darwinism has never been a really vital issue in psychology. Occasionally a theologian or a naturalist has inveighed against the Darwinian theory of mental evolution, but the psychologists as such have rarely uttered a protest. In view of the storm of vituperative scientific criticism precipitated by the publication of the Origin of Spccies, this fact is distinctly significant. Indeed, so much a matter of course have the essential Darwinian conceptions become, that one is in danger of assuming fallaciously that Darwinism has no important bearing on psychology. How Darwin's radical theories succeeded in gaining such easy access to the psychological sanctuary is a matter of distinct interest upon which a few speculative comments may be made.

It must be borne in mind, then, that Darwin's most revolutionary ideas on mental evolution did not appear until the publication of the Descent of Man in $187 \mathrm{I}$. This was nearly thirty years after Weber's epoch-making experiments on sensations, almost a score of years after the appearance of Lotze's medical psychology, sixteen years after the issuance of Spencer's evolutionary psychology and Bain's work on the Senses and Intellect, with its excellent presentation of the facts of nervous organization, eleven years after Fechner's publication of the Psychophysik, nine years after the first edition of Helmholtz's Sensations of Tone and seven years after his Physiological Optics. It was only three years in advance of the first edition of Wundt's Physiological Psychology. There had thus been rapidly growing during the preceding thirty years a disposition to view mental life as intimately connected with physiological processes, as capable of investigation along experimental and physiological lines, and finally as susceptible of explanation in an evolutionary manner. Moreover, by the time the Descent 
of Man was published the weight of scientific authority, so heavily against Darwin at the time of the publication of the Origin of Species in 1859 , had swung unmistakably to his support.

Another circumstance of probably more than negligible moment is found in the fact that the major interest of many psychologists has always been in the more narrowly analytical problems of mind. On these problems Darwinism has had little immediate bearing and has exercised only the smallest fructifying influence. Its contentions have seemed, therefore, to demand no very vigorous partisanship either one way or the other.

The effect of certain philosophic tendencies ought, no doubt, to be added to this brief survey of contributory influences, but the considerations already offered are probably sufficient to indicate in part, at least, why the publication of the doctrines of mental evolution expounded in the Descent of Man occasioned so little psychological flutter and in many quarters awakened so warm and enthusiastic a welcome. They also serve to explain why it is so difficult to assign with confidence the precise contribution of Darwin's thought to current conditions in psychology. Many convergent forces have been at work and the independent effects of each are hardly to be discriminated. Nevertheless, it is clear that Darwinism exercises a very potent influence in psychology, not alone as regards general standpoint and method, but also as regards certain specific doctrines.

In the matter of general method we may certainly attribute to Darwinism the larger part of the responsibility for the change which has brought into prominence functional and genetic psychology (including animal psychology), in distinction from the older and more conventional analytic psychology. Here again many influences have contributed to the final outcome, but it is fatuous to suppose that the genetic movement in psychology could have attained its present imposing dimensions had it not been for the inspiration of Darwin's achievements. The analytical methods will no doubt always retain a certain field of usefulness, and an indispensable one at that, but our larger and more significant generalizations, our more practically important forms of control over mental life are going to issue from the 
pursuit of methods in which growth, development and the influence of environment, both social and physical, will be the cardinal factors, methods which will in other words apply Darwinian principles with, let us hope, Darwin's tireless patience.

Darwin's more specific contributions to psychology may be grouped under three main headings: (I) his doctrine of the evolution of instinct and the part played by intelligence in the process; (2) the evolution of mind from the lowest animal to the highest man; and (3) the expressions of emotion. This is the chronological order in which these topics were given publicity by Darwin and we may properly adopt it in discussing the problems involved.

II.

The solution of the first issue, $i . e$. , the genesis of instinct and the part played by intelligence in such genesis, bears primarily perhaps on the field of animal psychology, but it certainly has a very definite interest for human psychology as well. At first blush it might seem that instinct is altogether a matter of muscular activities and neural mechanisms and that mentality has little or nothing to do with it. But a closer inspection of the actual manifestations of instinct serves to disabuse one's mind of that impression. Not only are human instincts honeycombed with psychic influences, but even animal instincts show themselves variable and adaptive to specific situations in ways which hardly permit any other interpretation than that of conscious adjustment. Take the imperious mating instinct as an instance. Among birds of many species there is every evidence that despite the impelling force of impulse, the female exercises a very definite choice in which to all appearances psychical impressions are potent. But the question still remains whether intelligence is a true cause in the production of instinctive acts, or whether it merely comes in occasionally to modify them. Herbert Spencer is cited with questionable justice as representing one extreme opinion in this matter. ${ }^{1}$ It is alleged that he holds that instinct is simply compound reflex action and that

${ }^{1} \mathrm{Cf}$. Romanes, Mental Evolution in Animals, p. 256. I find it difficult to be certain from a reading of Spencer's own statement just what position he really holds on this matter. 
it is always the precursor of intelligence. This is clearly the view of many modern physiologists and naturalists, of whom Bethe and Loeb are illustrations. From this standpoint consciousness is not essential to the formation of instinct. Among English and American writers G. H. Lewes and Cope represent the other extreme, maintaining that all instincts are originally intelligent conscious acts, from which conscious control has largely or wholly disappeared. Some authorities like Romanes have held that consciousness is at all times operative in instinct and that it is precisely the presence of consciousness which distinguishes instincts from mere reflexes. This general view held with sundry modifications by numerous writers, among others Wundt, is known as the 'lapsed intelligence' theory.

Darwin ${ }^{1}$ himself seems to have been less interested in the question as to whether mind is always present in instinctive reactions than in the question of its relation to the origin of instinct. His view seems to have been that instincts are in part due to the inheritance of useful habits consciously acquired, and in part due to the effects of natural selection operating on chance variations in conduct. Of the two he regards natural selection as the more important, because many instincts cannot have been inherited habits (e. g., those of neuter insects), and because the selection of slight variations in action through many generations seems to him plausible by reason of the conclusive evidence of a similar process in the evolution of structures.

Against the natural selection argument, as it pertains to the supposed preservation of incremental variations of a useful sort, it has been urged that in not a few instincts this is an impossible assumption, because the whole value of the instinct depends on the appropriate execution of each step in a long serieswof acts, each one of which alone, and any group of which apart from the others, is useless. Natural selection could only furnish an adequate explanation provided the whole series of complex acts sprang into existence simultaneously. To suppose that this occurs is to assume the miraculous. Stated abstractedly this

${ }^{1} \mathrm{Cf}$. Darwin, Origin of Species, Ch. VIII.; Romanes, Mental Evolution in Animals, Appendix. 
criticism appears forceful, but in view of our profound ignorance of the stages through which complex instincts have actually passed, it seem wise to be conservative in estimating the significance of the criticism.

It will be noted also that Darwin speaks quite explicitly of his belief that acquired habits are transmitted. The doubt which attaches to this doctrine in the minds of competent contemporary zoölogists is well known. Darwin quotes as illustrating his point the alleged acquirement of fear of man by birds in certain of the oceanic islands remote from the mainland subsequent to the coming of men and the pursuit of hunting. Certain cases of alleged transmission of characteristics as a result of mental training among dogs appear also to have weighed heavily in his mind.

If such acquirements are transmitted by heredity, then it must be admitted that this factor, together with the natural selection of such instinctive variations as arise naturally and after the manner of structural variations, would no doubt largely account for the phenomena with which we are familiar. But as we have just pointed out, difficulties beset both parts of this program.

A compromise view which is put forward with the joint authority of Morgan, Osborn and Baldwin, ${ }^{1}$ under the title ' organic selection,' maintains that consciously acquired habits are probably not directly transmitted, but that consciousness plays an indispensable part in the drama by enabling successive generations of creatures to accommodate themselves to the vicissitudes of life while the slow changes are taking place which finally issue in the completed instinct. Not only is consciousness operative in this way, but in all the higher forms of animal life it is held that conscious imitative activities also play a part, and with man a dominant part, in setting the racial pattern. Natural selection serves to lop off the feeble and incompetent, both among individuals and groups, while all this process is going forward, but the successful issue is fundamentally dependent on conscious reactions during the critical formative stages. In the midst of uncertainty and speculative ingenuity such

${ }^{1}$ Cf. Baldwin, Development and Evolution, especially Appendices A and B. 
as this, many minds will look with hope and a certain relief on the efforts of a group of zoölogists and physiologists - illustrated by Jennings and Loeb - who have made persistent and in no small measure successful attempts to modify instinctive behavior by experimental methods, thus securing at once some rudimentary insight into the mechanics of the instincts, instead of waiting for nature to reveal her secrets at her pleasure. In the lower organisms where such experimental control is most feasible, already the dependence of certain forms of instinctive behavior on conditions of temperature, light and oxygenation has been demonstrated and it hardly seems unduly optimistic to hope that through such means we shall ere long be able to substitute for speculative theories on the modus operandi of instinctive behavior something more nearly resembling knowledge. At present we can only say that we know with reasonable certainty that many instinctive acts are accompanied by consciousness, that practically all of them are variable within limits, that some of them appear to be modified by conscious forces, that possibly consciousness has played a part in the formation of some of them as it seemingly plays a part in their actual workings, that natural selection would certainly account for many instincts and perhaps for all.

We come now to consider Darwin's view of mental evolution.

III.

Darwin ${ }^{1}$ held that the mind of civilized man is a direct outgrowth of the animal mind. He maintained that from the lowest animal upward we find evidence of mental processes which increase in range and power, but do not change in kind, until we meet their most complete expressions in man. In man himself he finds again no evidence of aught but continuity of development from the lowest savage to the highest genius.

Darwin not only teaches the continuity of mental evolution from the lowest to the highest forms of animal life, he also urges the value of mental factors in the operation of both natural and sexual selection. Men and animals alike that were alert and intelligent in their adaptive acts would enjoy a larger chance of

${ }^{1} \mathrm{Cf}$. Darwin, The Descent of Man, Chapters III. to V. 
life and leave behind them a more numerous posterity. In those orders of animals where the female exercises selective control in the choice of a mate, he urges, as has already been indicated, that psychical factors enter in an important degree to determine the feminine preference.

His survey of mental characteristics on which these doctrines are based is somewhat naïve. The psychic qualities which he cites as a foundation for his statements are as follows: sensations, pleasure, pain, passions, emotions (terror, suspicion, fear, anger, courage, timidity, love, jealousy, emulation, sense of humor, wonder, curiosity), imitation, attention, memory, imagination (whose presence in animals he regards as proved by behavior indicating dreams), and reason, which in animals, he says, is closely allied with instinct. These categories are all taken quite simply and with no special effort to indicate precisely what may be meant by them. He contents himself by citing illustrations of animal behavior, which seem to him to indicate the presence of these several mental attributes.

He undertakes to fortify his general position by a refutation of the several stock arguments commonly advanced to support belief in the radical distinction between animals and man. Of these we may pause to mention only a few.

He meets the assertion that animals make no use of tools by citing the case of the chimpanzee who is said to use stones to open nuts, and by the case of the elephant who uses branches to protect himself from the assaults of flies. He might have cited many other similar cases, but it is to be observed that he makes no very satisfactory attempt to meet the further points that animals do not fashion utensils and that they do not use fire. For the present generation, however, this type of consideration has somewhat lost interest. He believes the opinion that animals do not form concepts and that they are incapable of making abstractions is not well founded. He cites as an instance of the appreciation by animals of something akin to an abstract idea, the attitude which a dog will assume in response to the exciting question, "Where is it?" The simple-mindedness of this conclusion must inevitably furnish amusement to the sophisticated animal psychologists of the present day. On the 
matter of language he occupies a position distinctly favorable to the possession of rudimentary language forms by animals. He cites the fact that many animals have calls expressive of emotion, and these calls he regards as essentially linguistic. $\mathrm{He}$ also mentions the use by parrots of significant words as a case demonstrating his contentions. Again, the sense of beauty has been held to be a purely human attribute. But this view Darwin feels is definitely controverted by the fondness which certain animals display, especially birds, for colors and plumage. The possession of conscience and the belief in God have frequently been urged as the sole possessions of humanity. To this assertion Darwin replies that the belief in God is not universal among human beings and hence not generically human, and the actions of many animals, notably dogs, indicate something closely akin to the feelings of conscience. To the contemporary psychologist all this sounds highly archaic and scientifically anachronistic and so no doubt it is. But in view of Darwin's extensive innocence of psychology, it represents, as he marshals his facts, an amazing range of original observation and a most intrepid mind.

In the last analysis, despite the statements of the preceding paragraph, Darwin regards the development of conscience, or the moral sense, as by far the most important practical distinction of man from the animals. He says, however, that any animal endowed with well-marked social instincts, such as the parental or filial affections, would develop man's conscience as soon as he developed man's intellectual capacity, or even approximated it. The social and gregarious habits of many animals obviously furnish an excellent point of departure for such a development. Moreover, sympathy, which plays an important part in all moral evolution, seems to be manifested by certain animals. There is therefore no evidence anywhere for radical differences between man and the animals.

It may be of interest to remark certain typical divergences from this general position in which, however, Darwin has found not a few loyal followers. Indeed, at the present time it is undoubtedly the case that most psychologists share Darwin's main convictions as to the continuity of mental evolution from animal 
to man, less perhaps as a result of careful scrutiny of the facts than as a consequence of a powerful drift from every direction toward the belief in a common origin for human and animal characteristics. We feel more comfortable nowadays in a world where simple and uniform rules obtain.

Probably the most persistent and most substantial point of dissent from Darwin is represented by writers who like Mivart ${ }^{1}$ hold that although men and animals have certain forms of conscious life in common, for instance, sentience and memory, man alone can frame true concepts, and man alone can use true signs, can create and use language. Only man'has ideas. Whereas we find essential continuity from the lowest to the highest of bodily forms, in mental processes we meet a real break, separating the human and spiritual, from the merely sentient and brute.

This type of view has always commended itself to a certain stripe of religious belief, because of its seeming provision for a somewhat super-naturalistic element in man, and its protest against regarding him, or at least his ancestry, as substantially on a level with the beasts of the field.

Moreover, it can summon to its support not a little apparently valid evidence wherein alleged instances of the animal use of language and signs are shown capable of another and more rudimentary interpretation. We are, of course, unable to intrude upon the inner workings of the animal consciousness, and it must be confessed that in so far as we judge by external conduct, few, if any, of the instances adduced to prove the formation by animals of concepts or of language really furnish unequivocal evidence of the thing to be proved. Meantime, it should be clearly recognized that this position, as advanced by Mivart at least, does not rest for its severance of man from the animals simply on the classical contention that he has a soul while they possess only minds. It is a distinction in the field of mind itself, which is here emphasized, an ascription to man, as his unique possession, of capacities which constitute the higher stages of cognitive activities.

Another divergent line is represented by the celebrated

${ }^{1}$ Cf. Mivart, The Origin of Human Reason. 
naturalist Wallace, ${ }^{1}$ who shares with Darwin a part of the credit for that revolution of opinion in the scientific world which generally is characterized with Darwin's name. Wallace is apparently willing to grant as a mere hypothesis that man's mind has developed pari passu with man's body, but he absolutely refuses to admit that natural selection could have brought this result to pass. He calls attention to three great familiar instances of alleged discontinuity in nature as suggesting that we should be scientifically hospitable to the idea of discontinuity. First, there is the breach between the organic and the inorganic, a breach which seems daily to shrink, but which has not yet been over-spanned. Then there is the equally marvellous break between the organic and the sentient, the conscious. And finally there is the break between mere sentience and rational intelligence - the distinction upon which Mivart dwelt so insistently.

Wallace cannot seriously call in question the possibility that natural selection should affect such mental qualities as quickness of eye and ear, accuracy of memory of former dangers and the like. It is the higher more definitely human qualities which apparently afford him foundation for his position. For example, what he calls the 'mathematical faculty' and the 'faculty for music' seem to him too remote from the life-subserving functions to have had any survival value, and unless they have such value, his position must be granted as having force against natural selection. On such grounds, in any case, he rests his contention that there is in man a spiritual essence not inherited from his animal forbears to whom he owes his bodily structure. By virtue of this essence human progress is possible and a spiritual life beyond the grave assured, for spirit cannot perish.

In reading Wallace one feels the presence of a vein of mysticism and the impelling influence of religious pre-possessions ... influences which may properly be given a hearing, but which must not be treated as standing on the same logical level with ordinary empirical evidence. Whether natural selection can reasonably explain mental development in its higher ranges, is however, a perfectly fair question and one which deserves, and from ethical writers at least has often received, serious consideration.

${ }^{\prime}$ Cf. Wallace, Darwinism, Ch. XV. 
It seems perfectly clear that certain familiar intellectual and emotional endowments would have had a very positive survival value both among animals and men. Those individuals who were mentally quick and inventive, who were courageous, cunning and pushing, would certainly be at an advantage over those who failed in these characteristics. Other things equal, the latter would live shorter lives and leave fewer progeny. When one takes into account the conditions of life under gregarious or social circumstances, one sees clearly how in a group the social virtues of sympathy, bravery, self-sacrifice, etc., may condition the dominance of the group over competing groups and consequently how a survival value may attach to these mental and moral characteristics. All this is familiar and trite and probably true. But what is to be said of Wallace's case as it concerns mathematical, philosophical and musical capacities, to the possessors of which men have customarily paid large respect? Wherein do such characteristics display a survival value, and if they have none such, how can natural selection account for their preservation and cultivation?

The reply, I believe, is quite in keeping with the reply as to the survival value of sympathy and pity and self-sacrificing bravery. In course of mental evolution, no doubt many characteristics are developed which are either harmful or useless. The congenitally insane illustrate the appearance of harmful forms. Other forms appear which may be useless or even harmful to the occasional individual, but to the group as a whole they are highly valuable and by virtue of this fact they secure perpetuity, either by social imitation, or by direct heredity. Now we have only to assume the appearance of a mental strain which has such social value, to expect with certainty that it will be encouraged in most of those who possess it markedly. Music and mathematics and philosophy do not represent such highly occasional mental sports as Mr. Wallace implies. A respectable amount of each of these capacities is latent in all normal individuals. Propitious surroundings are not always at hand and other more seductive interests often secure the field in advance, so that these capacities remain latent and undeveloped. But nothing is more certain than this, that if society did not at least consider itself 
benefited by the cultivation of these tastes, they would speedily disappear along with the taste for collecting scalps and wampum.

In other words, Mr. Wallace and others of his way of thinking take their natural selection too narrowly when they come to the higher ranges of mental life. They forget the social pressure which is there exercised, not to create but to develop certain capacities.

Still another view which not only accepts but magnifies discontinuity in natural phenomena is conceived not in the interests of any idealistic metaphysical or religious tenets, but rather in frank hostility to such. This is the view typified by Loeb, ${ }^{1}$ who believes that many of the lower organisms have no consciousness at all. This is a view which in more sweeping form Descartes long ago made famous, though on grounds quite different from those of Loeb. For Loeb, man's mind is a natural product of the evolution of animal mind, but animal mind itself begins not necessarily in the protozoa, but presumably at a relatively advanced point among the metazoa, at a point, namely, where we find creatures able to profit by experience, able to learn.

Accepting the analogy of many chemical phenomena in which a critical stage is represented, before and after which the resulting phenomena are apparently entirely discontinuous $(\varepsilon . g$., the formation of liquid from gas under given conditions ot temperature and pressure) he urges that until precisely the correct molecular conditions are represented in the protoplasm of the nervous system, no consciousness will appear. But the moment these conditions are given, mind will also be present. It is not necessary to assume mind, or associative memory, as he prefers to call it, wherever we find a nervous system, much less wherever we find protoplasm in a living state. We have a right to allege the presence of mind only when the actions of an organism indicate its presence, and our only criterion for this presence is, as was above stated, the capacity to learn by experience, to improve the reactions made to stimuli.

The difficulty with this criterion is practical, not theoretical.

$1 \mathrm{Cf}$. Loeb, Physiology of the Brain, particularly pages $213 \mathrm{ff}$. 
If one could always say with assurance that animals can or can not learn, the task would be easy. Unhappily such is not the case. Some animals learn to better a reaction after a few attempts, others require dozens of trials. Even the frog, whose intellectual capacities were once regarded as nil, has now been proved capable, under the advantages of higher education, of making some progress, but it is a progress which taxes both pupil and teacher, for it may require hundreds of experiences to improve even a very simple reaction. The criterion proposed, while theoretically admirable, leaves us as a matter of fact in much the position we occupied before, $i$. e., inability confidently to allege that any living creature is wholly lacking in mind. Even the lowly amœba manifests certain peculiarities of action which may betoken consciousness of a low order.

An examination of these variants on the Darwinian view of continuity in mental development leads one to feel that the balance of probability distinctly favors the original formulation. Not only does modern psychology disclaim in man at least any such sharp lines between conceptual thought and the lower levels of sentient mental life, as Mivart and Wallace postulate, it has on the contrary expended no little effort in analyzing and defending the presence of just these conceptual processes in the sensory and perceptual activities of mind. Binet's ${ }^{1}$ essay on the psychology of reasoning is a typical example of this tendency, exhibiting as it does the implicit reasoning process involved in every definite perception. To perceive that this object before me is a desk, involves identifying this present visual experience with antecedent visual experiences in a way which closely resembles certain phases of the process in syllogistic inference. Nor has this tendency in psychology been in any way influenced by partisan Darwinian prepossessions, so far as I know. It has been the inevitable outcome of penetrating analysis. The use of conscious meanings does not suddenly burst forth full-blown in a mind which before had given no indication of such an achievement. The simplest mental acts which as human beings we can detect in ourselves have some increment, however small, of this consciousness of meaning, this embryonic form of con-

${ }^{1}$ Binet, La Psychologie du Raisonnement. 
ceptual thought. Nevertheless, it must not be forgotten that animals have certainly not been as yet proved to reason in human ways. On this score Mivart and his cohorts must be given their dues.

Nor is the dividing line which Loeb has proposed likely to result in any radical alterations in the general Darwinian position. For not only do we find it difficult to use the criterion Loeb offers, i. e., educability, but in point of fact we have considerable evidence at hand to show that even the lowest animal forms modify their behavior somewhat to meet changed conditions, and that these modifications are of a kind which in higher animals would be regarded as indicative of the presence of consciousness.

IV.

This brings us to the work on emotion. In his treatise on The Expression of the Emotions Darwin has brought together with characteristic patience and industry the most extended array of observations bearing on the subject, an array which has been of notable value to the defenders of the James-Lange theory of emotion. As finally put forth the work is a defense of three familiar theses concerning emotional expressions. The first holds that serviceable bodily reactions become habitual and become associated with the state of mind in connection with which they arose. When the mental state recurs, the bodily reactions recur also, although they may long since have lost any immediate and obvious utility. The clenching of the fist and the showing of the teeth in anger illustrate this conception. The second thesis, that of antithetic action, maintains that a state of mind opposed to one calling out a definite bodily attitude may evoke an opposite bodily attitude. As an illustration may be cited the fact that an angry cat naturally lashes its tail from side to side. On the other hand a cat which is pleased carries its tail erect and stiff. The third thesis, that of nervous overflow, holds that apart from the two previous principles of explanation, conditions of emotional excitement are prone to release more cortical energy than can be effectively disposed of in the usual ways, and the superfluity pours out in muscular contractions of the most various kinds. 
So far as concerns the adequacy of these explanatory hypotheses, it may be said that in the light of our present knowledge the first affords a highly probable account of certain emotional reactions, while it is quite inadequate satisfactorily to explain others. The second hypothesis has always been viewed askance, as something of a scientific tour de force, while the third, which Darwin himself treats rather as a catch-all to take care of cases found bothersome to handle by his first two hypotheses, is probably of much more fundamental import than he imagined. In any event later writers have been unable to improve materially upon Darwin"s catalogue of the causative influences provocative of our emotional attitudes.

\section{V.}

In conclusion we may venture a brief comment upon the methods now current in the study of evolving mind and more particularly upon the methods and points of view now dominant in animal psychology. A few words may also be added upon a group of problems suggested by Darwin's work.

The most marked and unmistakable change which we notice in method is the somewhat aggressive skepticism now everywhere entertained for the anecdotal foundation on which many of the early zoölogical doctrines about animals were based. Darwin himself quotes numerous tales to substantiate his positions and his disciples have far outdone the master. This condition of things has led not unnaturally to a reaction in favor of laboratory experiments and observations under conditions of control. To this procedure there is never lacking acrimonious protest on the part of those who hold that only under the conditions of nature can the intimate facts of animal life be seen and understood. No doubt there is a large measure of justice in this protest. But fortunately it is now possible in many of our laboratories and zoological stations to simulate with large success the conditions of life which are natural to many animal forms. The result has been a wealth of new material which promises quite to revolutionize many phases of animal lore. It seems not unreasonable to anticipate that the effect of such work will not only be felt in the direct increase 
of our reliable information gained through these channels, but also that the observation of animals in a state of nature will be rendered far more intelligent and precise by virtue of the suggestions which will be gained from work of this type. Certainly such work has already brought us new and more exacting standards of accuracy and taught us an invaluable caution and conservatism both in inference and in generalization.

Conspicuous among the many interesting psychological problems suggested by Darwin's work is that of the determination of mental types, species and genera, following rudely the analogy of species and genera in zoölogy. The practical difficulty in defining a species need occasion us no concern, because the idea of species has had great value, despite the perplexities attached to the satisfactory differentiations of particular classes. If the type of intelligence manifested by an animal be contingent upon the structure of its nervous system, as is apparently the case, it would seem to follow as a reasonable inference, that we might expect to find groups of animals evincing in their behavior psychic characteristics of a similar pattern, just as we find forms of nervous system highly similar to one another. It is of course conceivable that in different animals different nervous structures should function to produce similar psychic behavior. But even recognizing this possibility, it still ought to be feasible to group creatures together as belonging to various great psychical type-forms.

At present the common divisions follow other lines. Animals which belong to the same family, e. $g$, the dogs, are thought of as resembling one another in general mental pattern and as differing from other animals partly in their instincts, but partly also in their capacity to learn non-instinctive reactions. This practical view of the matter leaves us with as many main patterns as there are genera and with no explicit and tangible description of any one. The other line of demarcation consists in cross-sectioning such a division as the preceding by distinguishing between such psychical characters as sentience, memory and reason, ascribing all these attributes to the higher creatures and denying one or another to the lower creatures. Amcba may be thought to have sentience, but not reason and 
only dubiously memory. The pigeon has sentience and memory, but probably not reason, whereas men and possibly some of the higher animals have all three capacities.

Obviously neither of these modes of classification affords us any real insight into psychic types. If Darwin's fertile investigations are to bear fruit in this direction in psychology, we must be able to portray the entire range of mental processes belonging to the great divisions of animal life, to show where and how these dividing lines part company with those which now bind animal forms together on structural lines. For ordinary zoölogical purposes the dog and the elephant have little in common except their mammalian hall-mark. But in their psychic types they may be very similar.

Such types may clearly be grouped around various central factors. Animals in which the so-called 'distance receptors' (auditory, visual, olfactory) are well-developed, may present a pattern with the psychic life all grouped about these processes. In other animals the 'contact and proprio-ceptive' organs may be the centers of psychic life and in consequence give rise to quite another mental pattern. In one or in both, the psychic operations may be of the most rudimentary and immediate sort, or they may, on the other hand, involve processes comparable with the simpler forms of human inference. The patterns may vary again in dependence upon the relatively large or relatively small amount of purely instinctive and reflex activity. They may vary with the phylogenetic antiquity of the form, newer types being more plastic than older ones. Many other principles of grouping will readily suggest themselves.

At the present moment we have the beginnings, but only the beginnings, of the necessary data for the solution of this general problem. We have learned, for example, that the mere presence of a sense organ does not argue such a use of it as casual inspection would suggest, much less such as is suggested by the analogy of human sense perception. We have accordingly learned caution in assuming that the sensory activities of animals involve the sort of consciousness which we know in ourselves. Indeed our whole tendency now-a-days is to recognize and frankly admit, that inasmuch as we must infer the 
psychic operations of animals wholly in terms of their behavior, we are under peculiar obligation to interpret their activities in the most conservative possible way. We know that the 'trytry-again, method' is the one commonly used by animals in solving laboratory problems. But we are for the most part profouidly ignorant as to just what occurs when progress is actually made, what sensory avenues are most important for giving information and how far the counterparts of human inference may at times be present. To secure these and dozens of other items of information needful for the execution of the program proposed will require long years of patient labor. Nevertheless, until this work is done, we shall remain powerless to describe the great stages of developing mind. The task is eminently worth while and is certain to be accomplished. Only when it is accomplished will it really be possible to entertain an intelligent judgment concerning the fundamental contentions of Darwinism concerning the evolution of mind. 